\title{
Training Successful Paraprofessional Copy Catalogers
}

\section{By Colleen Valente}

This paper argues for an incremental, progressive approach to teaching an inexperienced paraprofessional cataloger the basic skills required for copy cataloging. It demonstrates how to devise a training plan that is logical and progressive and argues that the plan should be based on a thorough analysis of the skills and knowledge required by the job. It then describes a specific approach to teaching the terminology of cataloging, Machine-Readable Cataloging (MARC), and International Standard Bibliographic Description (ISBD) punctuation. These three are the basic skills most copy catalogers will need first, and their mastery should precede training for more complex skills.

$\mathrm{H}$ ow do we teach anyone to catalog? Whether it is the professional librarianin-training or the displaced bank teller who takes a job on the lowest rung of the paraprofessional ladder, at some point everyone who has ever created or reviewed a bibliographic record needed training. In the case of paraprofessional staff, the challenge is daunting. How do we help the new employee successfully negotiate the training required to develop the necessary skills? Today we take for granted that paraprofessionals in technical services will do work that once was done only by librarians. While librarians were then freed to do more professional work, staff jobs were made much more complex and the training for them a lengthy process. Bednar and Stanley addressed this fifteen years ago when they noted that "even the entry level support staff positions in cataloging and acquisitions have become quite technical in nature and often require training periods of six months to one year."1

This paper describes an approach to training that begins with the development of a logical, progressive training plan for paraprofessional staff in their first days and weeks on the job. It then describes specific ways to teach the basic skills, Machine-Readable Cataloging (MARC) and International Standard Bibliographic Description (ISBD) punctuation that virtually all copy catalogers need before they are trained to apply Anglo-American Cataloguing Rules (AACR) or any other complex skills that their position might require. This approach grew out of experience I gained originally from teaching German, which I subsequently employed in the training of new paraprofessional catalogers. While this paper discusses only very basic skills, the principles of logical progression and practice described here are applicable to learning any other cataloging skills that are needed in a given position. The techniques described here can also be easily adapted for use with new professional catalogers. However, professionals start with a decided advan-

Colleen Valente (cvalente@aum.edu) is Head of Technical Services, Auburn University at Montgomery, Alabama.

Submitted September 17, 2008; returned to author October 18, 2008 with request for revisions and resubmission; resubmitted February 24, 2009, reviewed, and accepted for publication April 4, 2009. tage because they bring theoretical knowledge with them that a staff member with no exposure to library work must acquire on the job.

Thus this paper is concerned with the true neophyte to the world of libraries and cataloging. It suggests that the initial training of a new copy cataloger be approached in much the way a teacher instructs beginners in a foreign language. 
Students proceed from the most basic concepts to more complex concepts in a logical manner. The foreign language teacher puts together a syllabus for each course; the trainer needs to design a progressive training plan that lays out what the employee needs to learn to move from one step to the next.

The planning that precedes training determines how quickly and successfully new copy catalogers can master the necessary skills. A careful approach to laying a solid foundation of skills and theoretical understanding of why we do what we do is critical. Training copy catalogers on the job from the very first day is common and often involves having them sit with someone and watch how the job is done. Such an approach has limitations if it is the only mode of training. If the items are not preselected to teach concepts in a logical manner, training that proceeds logically from simpler to progressively more complex concepts is difficult. Building in the repetition that is so important to learning also is challenging.

From the outset, the trainer must look at the job, determine what skills it entails, and then determine the order in which those skills need to be mastered. A systematic approach to teaching basic skills and proceeding logically from the easier to the more complex skills helps ensure that nothing is omitted or taken for granted. The trainer will also want to make sure that the new employee learns the value of the work catalogers do and how cataloging fits into the library's mission. Because attitudes toward the job and the organization are shaped in the first days and weeks on the job, the orientation new employees receive should be seen as an integral part of their training. The investment of planning time that the trainer must make is considerable, but the effort will be repaid.

While the cliché that great teachers are born (not made) may be true, training is a skill that can be learned. The following literature review will describe resources in the education and management literature as well as in the library literature that can point trainers to helpful resources and give them tools for planning or revising a course of training. In addition, techniques for analyzing the specific job and associated tasks for which the new cataloger will be responsible will be described to demonstrate how a training plan can be developed that moves a trainee in a logical progression from skill to skill.

\section{Literature Review}

The use of paraprofessionals in roles that were once performed by professional catalogers is well documented and has long since ceased to be controversial. A significant share of the library literature concerned with staffing issues in libraries in the 1990s describes their growing use. ${ }^{2}$ The use of paraprofessional copy catalogers for everything from reviewing simple Library of Congress cataloging to creating original records spurred concern that their status, training, continuing development, and pay needed to be reconsidered. While the need to train was acknowledged by virtually all writers, the emphasis was on what paraprofessional catalogers needed to know to take on increasing responsibilities, not on how to teach them.

Bénaud, writing in 1992, noted that while smaller libraries made less use of paraprofessionals, they were doing much more of the work that used to be done by professionals in larger libraries. ${ }^{3}$ Various reasons for this were being offered in the literature. Some believed that it had become necessary because professional catalogers were increasingly taking on managerial roles. Others suggested that librarians were finding that the requirements of faculty status (committee work, publication, and teaching) eroded the time available to them for cataloging. Bénaud argued forcefully that paraprofessionals would be able to master all cataloging skills if allowed to do so, and she expressed the belief that "on-the-job training is by far the most effective way to learn to catalog." Beyond writing that training both professional and paraprofessional catalogers proceeds by progressing from simpler material to more complex material, she did not address the specifics of how to train.

In 1996, Younger offered a historical overview of the use of paraprofessionals in libraries. ${ }^{5}$ She discussed obstacles, including training, associated with redistributing cataloging responsibilities, but did not explore the details of how these obstacles might be overcome.

In 1992, Oberg, Mentges, and McDermott conducted a survey of 467 libraries to examine the status and working conditions of paraprofessionals and to determine the skills and competencies paraprofessionals needed. ${ }^{6}$ The authors discovered that 92 percent of large research libraries used paraprofessionals to perform copy cataloging while more than 30 percent used them to do original cataloging. In a later article, Oberg observed that the use of paraprofessionals had grown considerably since his 1992 survey and that their new roles and responsibilities made staff training and continuing development even more important. ${ }^{7}$ Rider examined the duties of copy catalogers in 1996 and came to the same conclusion-paraprofessionals were revising copy and creating original records. ${ }^{8}$ She found that the pressure to streamline cataloging and reduce backlogs had led to outsourcing, cataloging at the point of receipt, and pressure in-house for catalogers to accept copy from other sources without the scrutiny such records traditionally received. Because copy catalogers already possess relevant skills upon which to build, they could be trained to handle more complex records. She also assumed that they would be trained on the job and observed, "While librarians still debate the value of experience vs. education (in the form of the M.L.S. 
degree), LC's Robert Hiatt has noted that on-the-job training is one-on-one and progresses from simpler to more complex cataloging as additional rules, practices, and procedures are introduced." "

Bordeianu and Seiser surveyed fifty-eight ARL libraries to see if they could identify what minimum education and experience levels were required for paraprofessional catalogers. ${ }^{10}$ They discovered that only 19 percent of the responding institutions required a postsecondary degree. The rest looked for either no postsecondary training or some combination of education and experience. The authors concluded from this that "the fact that a relatively low number of libraries require postsecondary degrees implies that the workplace is still the preferred place to learn cataloging."

The literature reveals virtually unanimous agreement on the skills paraprofessionals need to acquire. Depending on the specific level of cataloging that they have been hired to do, they must learn to use the local integrated library system and the library's bibliographic utility, they must learn the AACR and how to apply them, and they must learn MARC and ISBD punctuation. Paraprofessionals who do original cataloging need to learn subject heading assignment and how to do authority work and classification as well. Yet one finds little reflection on how best to teach these skills beyond general agreement that progressing from simpler to more complex cataloging is necessary and that this will usually be accomplished one-on-one. A recent, informal request for information about training copy catalogers on Autocat lends support to the conclusion that a learn-bydoing apprenticeship model is still the usual mode of training, though the number of responses received (eight; six from college and public library trainers, one from a vendor, and a copy cataloger) was far too low to be statistically significant. ${ }^{12}$ Nevertheless, the tenor of the responses is consistent with the literature and with my own observations during the last two decades.

Library literature offers little advice about how to train. It is more often concerned with the competencies training should inculcate in professional catalogers. The Association for Library Collections and Technical Services has published a detailed description of the competencies professional catalogers need. ${ }^{13}$ In one of the few articles that does offer specific advice, Hudson restates the need to move from simpler to more complex copy and emphasizes the need to revise the new cataloger's work promptly so that errors can be pointed out and corrected. ${ }^{14}$ In her estimation, even new professional catalogers can be expected to need at least six months to a year to complete training, depending on how well they have been trained in subject analysis, MARC, and AACR in library school. In more recent years, several interesting articles from both a cataloging and a systems perspective point to a growing awareness that there are other modes of training that can be successfully employed.
Kriegsman described the training that staff and volunteers underwent during an early stage of the Colorado Digitization project. ${ }^{15}$ The project required staff and volunteers in a number of different venues (libraries, museums, historical societies, and archives) to learn to create catalog records for the materials being digitized. Trainers learned that they needed to ensure that participants understood why standards are necessary, use terminology that all could understand, and use a variety of training approaches to accommodate different learning styles. Ward and Dowski described a project to train library school students without cataloging experience to assist with the cataloging of electronic resources at the library of the State University of New York at Buffalo in 2001 and 2002. ${ }^{16}$ They made heavy use of the technology available to them to make the cataloging process more efficient by creating templates, constant data records, and macros to speed up cataloging. They gave the students MARC cheat sheets to help prevent coding errors and assigned collections of resources with a high probability of having bibliographic records in the OCLC database for print equivalents from which the students could derive records, instead of having to create a completely original record. Their success demonstrates how careful tailoring of the training plan facilitates learning.

Two articles addressing training for changes in automation also yield helpful insights. Reflecting on training staff for changes and upgrades to systems and software, Balas observed that the staff with whom she had worked had a variety of training preferences. ${ }^{17}$

Some want a formal, hands-on training session; others prefer to be given the opportunity to work with the technology on their own and will even read the documentation; and still others are not happy until someone sits down with them one-onone and walks them through the procedures. And while it seems that everyone wants the security of printed instructions, once again there is no agreement-some want brief instructions while others want them to be more detailed and to anticipate the mistakes they might make. ${ }^{18}$

Puffer-Rothenberg offered additional useful training advice in a discussion of preparing staff for a system migration. ${ }^{19}$ Odum Library at Valdosta State moved from a DOS-based cataloging module to an integrated library system using a Windows interface in 2001. The staff were concerned about their ability to adapt to the new system and to the changes in workflow it would cause. By taking an incremental, small-steps approach to training and by providing documentation to allow further practice after each session, trainers enabled the staff to make a smooth, low-stress transition to the new system. 
New employee orientation is not usually viewed as part of training, but the first days and weeks new employees spend in the workplace will permanently influence their attitudes toward the job and the organization. Far from being an initial task that new hires must take care of before they can start doing their real work, it should be considered part of the job. The welcome that new employees receive will play a very important role in their adjustment to the organization and the likelihood that they will stay. Craig, writing in Personnel Today, cited one retention expert who said "that between $20 \%$ and $25 \%$ of employees leave their new job within a year, to a large extent due to not feeling part of the organization." ${ }^{\text {"20 }}$

Too often, orientation consists of little more than a lot of paperwork. Orientation has a much more important role than assuring that the new employee has an ID, a parking permit, and a W-4 on file. Orientation may be described as "the process by which newcomers make the transition from being organizational outsiders to being insiders. ${ }^{.21}$ Not only does orientation help the new employee become an integral part of the workplace, it demonstrates his or her importance to it. Mossman pointed out that "from the beginning, an orientation program sends a clear signal that the organization is committed to an employee's success. ${ }^{\text {"22 }}$

In describing the orientation developed at North Carolina State University Libraries, Ballard and Blessing were emphatic about the benefits of a well-thought-out program, which they saw as part of the socialization process that all employees undergo when they join an organization. Socialization, which has long been a topic of interest in the management literature, has been defined in various ways. Ballard and Blessing wrote that socialization is "the process by which employees learn about and adapt to new jobs, roles, and the culture of the workplace. ${ }^{.23}$ DiMarco also recognized how important orienting new employees to their environment is, noting that "every institution has its own culture, policies, and procedures. An orientation plan that takes this into account will make a new employee's transition to your organization much less stressful for all involved."24

A formal orientation may only last a couple of hours on an employee's first or second day. Sometimes, the amount of information packed into it is so overwhelming that newcomers are actually disoriented, which can only increase the anxiety most new employees feel as they learn their new jobs, meet new people, and try to find their place in the organization. The management literature, which is very concerned with recruiting and retention issues, is starting to take a much longer view of orientation. "Orientation in its most ideal form is on-going. It starts with recruitment and selection, and continues throughout the new employee's first year on the job," noted Hacker, who then outlined a number of strategies to make new staff feel welcome. ${ }^{25}$

The management literature is an excellent source of concrete guidance in preparing formal and systematic training programs based on a thorough analysis of a given job and the tasks that make up that job. The education literature provides insight into how adults learn, which must be taken into account in developing a training plan. Both literatures share a deep interest in how and why adults learn. While education and training have much in common, they are not the same thing. The design of a new employee's training will be driven by the outcome desired: "Training aims to provide knowledge and skills ... which are needed to perform specific tasks," while "education usually provides more theoretical and conceptual frameworks designed to stimulate an individual's analytic and critical abilities."26

Understanding some of the underlying theoretical principles of how learning takes place is helpful. Many theories that have been developed and refined over the last century tend to cluster around certain core ideas. Laird, Naquin, and Holton identified five metatheories in their very helpful book, Approaches to Training and Development: New Perspectives in Organizational Learning, Performance and Change. ${ }^{27}$ They called them metatheories "because they apply to learning in all settings, for all age groups and to all types of learning events." ${ }^{28}$ Two of the metatheories they identified are particularly relevant to cataloging: behaviorism and andragogy. Training grounded in behaviorism will be familiar to everyone who has taken a beginning foreign language class. Certain outcomes are expected (e.g., the correct application of rules), reinforced, and rewarded. Any rule-based activity or any task that must be performed in a certain way is behavioristic. The desired outcome of the training is competency in the skill to be learned.

Andragogy is a theory of how adults learn that has had a profound effect on training theory. The term, coined in 1833 by the German educator Alexander Kapp, was popularized in the United States and Britain by Malcolm Knowles in his books The Modern Practice of Adult Education and The Adult Learner.$^{29}$ Andragogy, as conceived by Knowles and reported by Laird, Naquin, and Holton, has six principles:

"1. Adults need to know why they need to learn something before they learn it.

2. The self-concept of adults is heavily dependent upon a move toward self-direction.

3. Prior experiences of the learner provide a rich resource for learning.

4. Adults typically become ready to learn when they experience a need to cope with a life situation or perform a task.

5. Adults' orientation to learning is life-centered, and they see education as a process of developing increased competency levels to achieve their full potential.

6. The motivation for adult learners is internal rather than external." ${ }^{30}$ 
Cataloging does not offer the trainee much opportunity to direct his or her own learning. Although self-directed learning has been a popular training strategy for yearsparticularly for employees who need to acquire new skills in a job they are already doing-finding ways that a new employee can take charge of learning new skills that depend on the accurate application of rules is difficult. However, a trainer can help the new copy cataloger understand why the rules exist and what their value is. Integrating new employees into a cataloging department should include making sure that they understand how cataloging fits into the mission of the library and why the work is important.

\section{Analyzing the Job}

The development of a successful training plan first requires an analysis of the job. The trainer must thoroughly understand the job that needs to be done. Even when experienced catalogers do the training, they may not fully understand all aspects of the job that copy catalogers do, particularly in large libraries where they may have less opportunity to work directly with all levels of employees. During the planning of the new staff member's training, the trainer should speak to other staff that do the same job to ensure that all the tasks that they routinely undertake are reflected in the training plan.

An analysis of the job and the various tasks that make up the job are critical to developing a successful training plan. The management literature is particularly helpful in describing this process, even though much of it has been written from the perspective of trainers concerned with jobs in business and industry. For example, the Journal of European Industrial Training published an issue devoted to the subject, and it is an excellent source of information. ${ }^{31}$ One section describes the questions the job analysis should answer:

"1. What duties does the job include?

2. What tasks make up the job?

3. How is each task accomplished?

4. Why is each task performed?

5 . In what order are the tasks performed?

6. What elements make up the tasks?

7. What equipment, materials, and supplies are used?’32

An example drawn from practice will be useful in illustrating what such an analysis will reveal. In my library, the library assistant in the acquisitions unit is also a monographic copy cataloger. An analysis of the job will reflect that it is made up of two duties: acquisitions and cataloging. In turn, cataloging and acquisitions also must be analyzed to see what tasks are done and what skills or knowledge are required to do them. For example, the assistant is responsible for the acquisition of all firm-ordered books. Thus she places orders after determining availability and price from the vendor, creates purchase orders, receives those orders, and approves their payment. She then catalogs the books she has ordered if they have acceptable copy. The skills required to carry out each task make up its elements. In this case, the elements are the ability to use a computer and the ability to understand and follow written procedures for both cataloging and acquisitions, as well as use the MARC manual.

Task analysis determines what skills are required to complete the task successfully. It can reveal that even simple tasks are not always easy. For example, the first task that the acquisitions library assistant undertakes is preorder searching, that is, checking the catalog to see if a requested book is already in the collection prior to placing an order. This seems easy and is usually the first task assigned to a new employee in that position. However, an analysis reveals that the assistant needs to know

- how to search the local catalog to see if the library already owns the book;

- how to understand MARC coding well enough to find the needed information, that is, identify the important match points (beyond title and author), such as date of publication and edition statement;

- how to distinguish between editions; and

- how to recognize an electronic version and apply the library's policy regarding the purchase of books that are available electronically

Thus this simple task comprises four elements, and all require specific training that the assistant must receive before being expected to do preorder searching successfully.

Once the assistant has determined that the library does not own the book, the order can be placed, which is the second task associated with acquisitions. Ordering requires another set of skills that must be analyzed. When the books ordered have been received and the invoices approved (yet another task with associated skills that must be mastered), the assistant is ready to carry out copy cataloging. The trainer must be clear about all the tasks and the skills required to develop a comprehensive training plan.

\section{What Does a Copy Cataloger Do?}

While the degree of editing a copy cataloger may do can vary markedly in different libraries or between different levels of staff working with more complex records or multiple formats, the commonalities are such that the task analysis that reflects what the library assistant in my department does will be familiar to most catalogers. An examination 
of the skills needed to complete each task reveals that the cataloger must perform the following tasks:

- Compare the book that has been received with the WorldCat record that was downloaded and used to create the purchase order. Does the record match the book in hand? (Skills needed: ability to search the local database; ability to determine whether the book and record match)

- Search for a WorldCat record that does match if the one originally downloaded does not. (Skills needed: ability to search in WorldCat; ability to identify the appropriate record if multiple records are found)

- Download and overlay the inappropriate record in the local database with the appropriate one if found. (Skill needed: ability to overlay the bibliographic record in the local database to preserve the link between it and the purchase order)

- Determine that the title, other title information, and statement of responsibility have been transcribed from the title page of the book correctly. Make any corrections needed. (Skills needed: ability to proofread; understanding of the significant bibliographic elements on the title page; ability to edit in the local database)

- Look at all access points to see if they are spelled correctly. Correct any errors noted. (Skills needed: knowledge of what access points are; knowledge of how to edit the record in the local database)

- Check the MARC coding of all access points and correct as necessary. (Skills needed: knowledge of the MARC codes, indicators, and subfields involved; ability to edit in local database)

- Add bibliography note if missing. (Skills needed: knowledge of the MARC codes required in both the fixed and variable fields; ability to edit in the local database; ability to formulate the note)

- Add tables of contents to books in certain series that we have identified as being of particular value to our students. (Skills needed: knowledge of the policy regarding tables of contents; knowledge of the MARC codes and ISBD punctuation required; ability to edit in the local database)

- Add any bibliographically significant names or corporate bodies found on the chief source to the record. (Skills needed: ability to understand which elements on the title page are significant; knowledge of the MARC codes required; ability to edit in the local database)

- Create the holdings record. (Skills needed: ability to create a holdings record in the local database and edit it; knowledge of the MARC codes used in the holdings record; knowledge of the notes required in the holdings record)

- Write the local bibliographic record number in the book in the upper right hand corner of the first leaf. (Skills needed: understand what to do if the page cannot be written on; know where to find the system supplied record number)

- Send the book to end processing

Most of the elements of this task are more complex than they might seem at first glance. For instance, the first element of the task requires the copy cataloger to determine whether the record downloaded when the order was placed and the book that was received match. That, however, requires the copy cataloger to know what constitutes a match. If we look at this through the eyes of someone new to cataloging, we will see that much of this is not self-evident and must be learned. The cataloger must know how to do the following:

- Identify the title without being confused by the layout or typography

- Decide if variations between the title proper on the title page and on the bibliographic record are cataloger transcription errors or if they indicate that the record and the book do not match

- Compare the ISBN on the record and in the book

- Check that edition statements match

- Check date of publication and distinguish dates of publication or copyright from printing dates

- Determine when differences in pagination are significant and when they are not

- Check the spine height and understand when a difference is significant

When tasks are considered element by element, it becomes much clearer what the new staff member must know to carry out the job. This enables the trainer to ensure that the plan takes no necessary skill or knowledge for granted and covers everything the trainee needs to know.

Once the job has been analyzed, some decisions have to be made about the overall training sequence. The task analysis has identified the skills that must be acquired, and the trainer needs to decide which elements of the task logically come first, second, and so on. The trainee needs to master each step from the simplest to the increasingly difficult. Although various sequences are possible, some steps obviouly must precede others In the case of a paraprofessional cataloger with no previous relevant experience, the trainer should make sure that the basics are covered thoroughly and that each is mastered before going on to more complex steps. 


\section{Orientation}

New employees usually begin their jobs with whatever orientation to the workplace the library or university provides. The first days and weeks in a new job are a critical period for new employees because their attitudes toward the job will be formed early. Orientation typically fills the new employee's day (or days) with a number of activities, such as touring the library and perhaps the campus, meeting with other staff, and attending to myriad administrative matters. In fact, it can be overwhelming. Thus some quiet time to sit down, ask questions, and talk about the library one-on-one with a librarian or an experienced staff member will be very useful. The sorts of matters covered by a formal orientation do not usually include such mundane questions as Where are the restrooms? Where can I buy a soft drink? Where is the cafeteria? As simple as these questions are, they are often overlooked. Anticipating them and offering the information before being asked can help make the first week much easier for the newcomer. A checklist that prompts new employees to ask questions that they might think are too silly to ask can be very useful. Figure 1 is a condensed version of the checklist I give to newly hired employees.

Time should also be found during the first week for an experienced cataloger or the department head to discuss the library and its mission with the new employee. Such a discussion should cover the department's role in helping the library achieve that mission. It should be the first discussion, though not the last, of the value of cataloging and the important role that copy catalogers play in helping to organize the materials that the library acquires. With some theoretical understanding of what the job entails and why it is important, the trainee will be better able to start learning.

\section{Terminology}

The first step must be to learn cataloging terminology. I learned early in my career as a German teacher that a well-thought-out lesson on, for example, the subjunctive, was incomprehensible to a class that did not know what the subjunctive is and only barely understood what a verb is. Verbs? Voice? Mood? These terms, the vocabulary of grammar, are as foreign to many students as the language they are studying is.

Misunderstanding the language or terminology of any field or subject will undercut a student's ability to make progress learning it. This is not unique to cataloging. An article in the journal Mathematics Teacher describes how many students perceive the terminology of mathematics as a foreign language. ${ }^{33}$ Not only must they learn unique words like "hypotenuse," but they must learn to differentiate the specialized meaning of words such as "table" and "limit" from the ordinary meaning of those words. The author
Please check off these items as you learn them. If you are unsure, please leave them unchecked. We will go over anything that has not been covered for you adequately on Friday.

a I know how to fill out a time card and where to find the time clock.

- I know where the cafeteria is.

- I know where to find a list of official university holidays.

a I know where the staff lounge and vending machines are.

- I know where to find a rest room.

- I have keys to the department and building.

๑ I understand the mission of the Technical Services Dept.

๑ I know who does what in Technical Services.

Figure 1. First Week Checklist (Condensed Version)

made the point that "students who are unable to negotiate discourse are unable to move forward in their learning." 34 Experienced catalogers sometimes forget that terms such as "series," "title proper," "access point," "collation," and so on, are equally foreign to most nonlibrarians. Making sure that new employees understand these terms is necessary if their training is going to make sense to them.

\section{Training Sequence}

The next steps will depend on the trainer's analysis of the job and the tasks associated with it. Training without reference to the actual sequence in which the job is performed may seem counterintuitive, but the latter is unlikely to be the most logical order for learning. If, for example, the trained copy cataloger's first step is to find a record in WorldCat that matches the book in hand, a number of skills will need to have been mastered prior to performing such a search and successfully locating a record. Teaching skills as discrete units allows the learner to concentrate on one skill at a time and master it.

\section{Training Activities}

Because overwhelming a beginner is easy, the amount of formal training should be limited. A training session should not last much more than an hour. Trainees should then practice what they have just learned. Ideally, feedback should follow practice as soon as possible with more practice assigned, as needed. Depending on how quickly the employee learns and whether or not other learning activities are being used (such 
as the interactive tutorials OCLC makes available), formal sessions might be limited to three or four times a week.

The reason for this is two fold. First, teaching a complex skill that involves many rules without making the inexperienced staff member feel incompetent is difficult. Students learning a foreign language for the first time in college are often surprised to discover how frustrated they are by their inability to express themselves in anything but the most elementary way. Similarly, many new catalogers are surprised by the frustration they feel learning an entirely new skill with its own rules and its own language. The rules are rigid and catalogs are unforgiving of mistakes. Unfortunately, too often the trainer appears to be rigid and unforgiving as well. New staff will ask why we do things the way we do them and why even (seemingly) minor errors must be caught and corrected. Trainers need to understand that adults will usually want to know why and should take the time to explain, even if the question goes beyond what the staff member needs to know.

Once the new staff member understands bibliographic terminology and has had an introduction to the local cata$\log$, MARC, and ISBD punctuation, "shadowing" — sitting with an experienced staff member and seeing and hearing about the task being done-comes into its own as a helpful training strategy. After the trainee has learned the most important terms and has become familiar with what a catalog record looks like, watching what the experienced staff member is doing makes more sense and puts the skills in context. Second, the trainee will necessarily be learning other aspects of the job and doing some portion of the work. The mix of theory, observation, and practice will reinforce what the trainee is learning while providing needed variety.

\section{From Theory to Practice}

Students in foreign language classes are very familiar with fill-in-the-blank exercises. Such exercises are used because they allow the instructor to focus on one very specific learning objective. For instance, German has prepositions that take the accusative case. An exercise might be designed to allow students to practice using accusative pronouns in prepositional phrases correctly. Such a technique can be readily adapted to many of the skills a cataloger needs to learn.

Because learning to speak the language of cataloging is so important, the trainer should begin with terminology. I sit down with each trainee and a cart of books. We go through them and identify title proper, other title information, author(s), and so forth. After this session is over, I ensure that this terminology has been mastered by giving the trainee ten to fifteen books and a stack of fill-in-the-blank worksheets on which to identify the bibliographic elements that are found on the title page and verso (see appendix A).
Only at the point that the essential terminology has been mastered do I move on to MARC and ISBD punctuation.

Fill-in-the-blank exercises are very effective in teaching both MARC and ISBD punctuation in manageable portions. I usually compare learning to catalog with learning a foreign language. Most trainees relate to this analogy because most of them have had at least a little high school or college foreign language experience and remember how challenging those first days and weeks were. The utility of drawing such an analogy has a solid basis in learning theory as a strategy to help adults acquire new knowledge. Maresh called this sort of analogy a metaphor and says that such metaphors facilitate learning because they link the known to the unknown. ${ }^{35}$ She noted that "Metaphors are intrinsic to the construction of new knowledge and lie at the heart of the creation of meaning. ... When we forge a connection between a new concept and a past experience, the concept is clarified and the mind is encouraged to explore it further. ${ }^{י 36}$ Anyone who has been initially overwhelmed by the strange sight and sounds of foreign words that slowly became meaningful will find the analogy helpful.

Because most new copy catalogers find the MARC format visually daunting, I normally start with it. I teach MARC tagging by introducing exercises that are limited to one or two MARC fields at a time, which I complete with the trainees. They are then given fifteen or twenty exercises drawn from the catalog to complete on their own by supplying the correct indicators and subfields. A simple MARC tagging exercise dealing with only one or two fields at a time would ask the trainee to supply the indicators and subfields in the following:

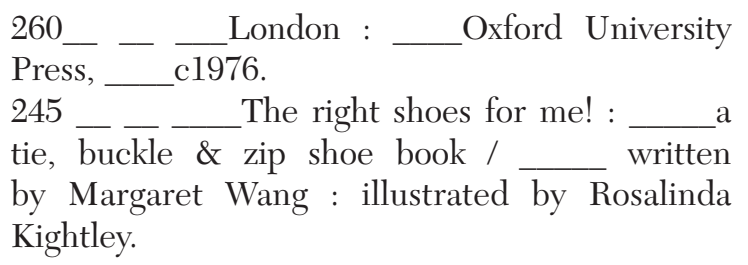

A follow-up session would include more complex exercises. They might include more fields or subfields that are seen less frequently. For example:

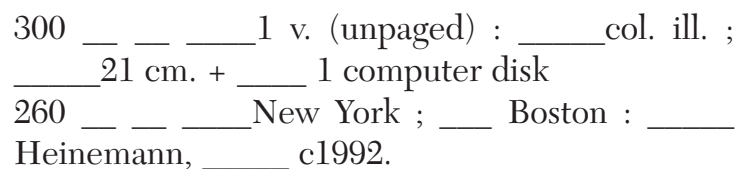

New copy catalogers receive a cheat sheet that lists the MARC fields and subfields that they need to know (see appendix B). Trainees use it to complete the exercises they are given. Normally, I allow a day for their completion and then review the work with them to provide feedback as 
quickly as possible. If the exercise was not successful, the trainee is given ten (or more) additional exercises. When they have been successfully completed, the trainee is ready to try more complex exercises in the following session.

ISBD punctuation is next, and it is taught and practiced in exactly the same way. I use many of the same records that were used in the MARC exercises; this time, the punctuation has been left out and the MARC tags remain. For example, a basic exercise would ask the trainee to supply the proper punctuation between subfields, indicating the necessary space(s) between subfields by drawing a delta $(\boldsymbol{\Lambda})$, in the following:

260 New York \$b Dover Publications, \$c 1987.

After the basic exercises are completed, the trainee moves onto more complex exercises. At this point, the trainee can be given two or more fields to punctuate, as in the following example:

$24514 \$$ a The right shoes for me! $\$ \mathrm{~b}$ a tie, buckle \& zip shoe book! \$c written by Margaret Want illustrated by Rosalinda Kightley.

260 _Atlanta, GA : __ Piggy Toes Press, c2007.

MARC coding and ISBD punctuation are skills that are learned by practice, and the trainee should be given as much of it as needed to demonstrate mastery over the course of the first couple of weeks of training.

Helping the new staff member feel like a contributing part of the department as soon as possible is important. Formal training should be mixed with guided practice as soon as the basics have been mastered. After learning how to search the local catalog and make changes to the bibliographic record, I give the trainee several books that have been preselected because the bibliographic record contains some error. The cataloger is told where or what they are, for example, a transcription error in the title field or a MARC error in the collation. Even though this is time-consuming, I find that going over the errors that have been corrected (or not) and explaining to the trainee why the original cataloger made the notes and the added entries that he or she made to be helpful. This will seem self-evident to an experienced cataloger, but it is all new to the trainee. It is also the easiest way I know to convey some sense of why we do what we do and how that work affects our catalog users.

After the basic skills have been taught, the new copy cataloger will be given a number of new books with which to work. The bibliographic records are then reviewed and mistakes the trainee made or failed to catch are reviewed. Because this revision can be stressful, initially I limit the amount of copy cataloging the trainee is given. Other work that needs to be done can be given to the trainee to enhance his or her learning. For instance, during slow periods staff may go into the stacks with experienced staff members, pull books with labels that are faded or coming loose, and bring them back to be relabeled. Experienced staff also will read the shelf from which they pull the books and can teach this skill to the new staff member. This is one useful way to involve others with the training. They help the new employee learn his or her way around the library and become familiar with call numbers at the same time.

While many training materials can be developed inhouse, resources on the Internet, most of them free, can be brought into the mix of learning activities (see appendix C). They are very helpful in bringing the newly hired employee up to speed. While materials created in-house and externally may have some overlap, both the repetition and the differences of approach to the subject matter are advantageous because they accommodate different learning styles. Some people prefer to work at their own pace. For them, interactive tutorials are particularly helpful. Others appreciate being able to read and study descriptions. Others will benefit from the frequent opportunity to test themselves along the way that many of these resources provide. All of them complement the training that goes on in-house.

I also try to send all staff at least once a year to the courses that our regional OCLC services provider offers. This is beneficial for two reasons. Such classes are an excellent way to give staff an opportunity to develop new skills, and they also are a way to refresh skills or provide retraining if necessary. In the latter case, staff members may find admitting confusion to an instructor outside the library easier than to their supervisor or peers. For new staff members, classes seem to be most valuable after at least three or four months of actual cataloging experience, since the classes usually presuppose some experience and tend to move along briskly.

Once a new cataloger is familiar with the language of cataloging, knows MARC and ISBD well enough to either use them correctly or consult the appropriate manuals, and knows what to add and what to correct on the bibliographic record, he or she is ready to work independently. Each cataloging supervisor needs to decide how long trainees must have their work checked. This decision is normally linked to the number of errors the cataloger makes. Frequent errors, particularly of the same sort, indicate a need for additional training. The evaluation of the training plan and any subsequent revision of it will depend on identifying any weaknesses and understanding where the training has been inadequate so that other strategies can be devised.

Assessing this approach to training is difficult. Since we cannot train the same person twice and compare the outcomes, determining which training method or combination of methods works best is difficult. However, one can 
reasonably assume that an incremental, progressive approach that looks for mastery of each skill before proceeding to more complex matters will provide a solid foundation for learning. Experience suggests that the more carefully planned and sequenced the training is, the better the results will be.

\section{Conclusion}

Training copy catalogers effectively requires advance planning. Trainers must think through the requirements of the particular job for which the new employee is to be trained. They must determine the skills that are required for successfully carrying out the job duties. The development of a training plan entails understanding how one skill builds upon another and ensuring that nothing the new staff member needs to learn is omitted or shortchanged. Saying that our employees are our most valuable resource is cliché, but it is nevertheless true. Training them carefully both with regard for the complexity of the skills that they must learn and with respect for the way adults learn makes sense. We must train with the person in mind as well as the work. The unit, the library, and the library's patrons are all served by a well-organized, accessible collection. Our staff play a vital role in helping the library achieve its mission and deserves to be trained with that role always in mind.

\section{References}

1. Marie Bednar and Nancy M. Stanley, "Hiring Tests for Technical Services Support Staff Positions," Technical Services Quarterly 11, no. 1 (1993): 3-4.

2. Martha Parsons, comp., Library Support Staff Issues Bibliography, American Library Association, www.ala.org/ala/ educationcareers/education/3rdcongressonpro/librarysupport staffissues.cfm (accessed Feb. 15, 2009); Rita Gibson, Library Paraprofessionals: A Bibliography, Council on Library/Media Technicians (June 2003), http://colt.ucr.edu/bibliography.html (accessed Feb. 15, 2009).

3. Claire-Lise Bénaud, "The Academic Paraprofessional Cataloger: Underappreciated?” Cataloging \& Classification Quarterly 15, no. 3 (1992): 81-92.

4. Ibid., 87 .

5. Jennifer Younger, "Support Staff and Librarians in Cataloging," Cataloging \& Classification Quarterly 23, no. 1 (1996): 27-47.

6. Larry R. Oberg, Mark E. Mentges, and P. N. McDermott, "The Role, Status, and Working Conditions of Paraprofessionals: A National Survey of Academic Libraries," College \& Research Libraries 53, no. 3 (1992): 215-38.

7. Larry Oberg, "Support Staff in an Age of Change: The Challenges of Tomorrow," Library Mosaics 10, no. 1 (Jan./ Feb. 1999): 12-15.

8. Mary M. Rider, "Developing New Roles for Paraprofessionals in Cataloging," Journal of Academic Librarianship 22, no. 1 (1996): 26-32.

9. Ibid., 29 .
10. Sever Bordeianu and Virginia Seiser, "Paraprofessional Catalogers in ARL Libraries," College \& Research Libraries 60, no. 6 (Nov. 1999): 532-40.

11. Ibid., 540 .

12. Colleen Valente, "Training Entry Level Professional Staff," online posting, Jan. 14, 2009, Autocat, autocat@listserv.syr .edu; the Autocat archives are password-protected (accessed Feb. 19, 2009).

13. Association for Library Collections and Technical Services, Training Catalogers in the Electronic Era: Essential Elements of a Training Program for Entry-Level Professional Catalogers, ala.org/ala/mgrps/divs/alcts/resources/org/trainingcatalogers .cfm (accessed Feb. 10, 2009).

14. Judith Hudson, "On-The-Job Training for Cataloging and Classification,” Cataloging \& Classification Quarterly 7, no. 4 (Summer 1987): 69-78.

15. Sue Kriegsman, "Catalog Training for People Who Are Not Catalogers: The Colorado Digitization Project Experience," Cataloging \& Classification Quarterly 34, no. 3 (2002): 367-74.

16. Diane Marie Ward and Craig A. Dowski, "Training MLS Students to Catalog," Computers in Libraries 23, no. 8 (Sept. 2003): 22-25.

17. Janet L. Balas, "Once More into the Breach: Revisiting Training (Again)," Computers in Libraries 25, no. 8 (2005): 43-47.

18. Ibid., 43.

19. Maureen Puffer-Rothenberg, "Training Copy Catalogers in Preparation for System Migration: An Incremental Approach," Technical Services Quarterly 21, no. 1 (2003): 31-38.

20. Tara Craig, "How to ..., " Personnel Today (Apr. 22, 2008): 31.

21. Talya N. Bauer et al., "Newcomer Adjustment During Organizational Socialization: A Meta-Analytic Review of Antecedents, Outcomes, and Methods," Journal of Applied Psychology 92, no. 3 (May 2007): 707.

22. Katherine Mossman, "Good Orientation Counts," Library Journal 130, no. 11 (June 15, 2005): 46.

23. Angela Ballard and Laura Blessing, "Organizational Socialization through Employee Orientations at North Carolina State University Libraries," College \& Research Libraries 67, no. 3 (May 2006): 240.

24. Scott R. DiMarco, "Practicing the Golden Rule: Creating a Win-Win New Employee Orientation," College \& Research Libraries News 66, no. 2 (Feb. 2005): 110.

25. Carol A. Hacker, "New Employee Orientation: Make it Pay Dividends for Years to Come," Information Systems Management 21, no. 1 (Winter 2004): 90.

26. Roger Buckley and Jim Caple, The Theory and Practice of Training, 5th ed. (London; Sterling, Va.: Kogan Page, 2004): 7.

27. Dugan Laird, Sharon S. Naquin, and Elwood F. Holton, Approaches to Training and Development: New Perspectives in Organizational Learning, Performance and Change, 3rd ed. (Cambridge, Mass.: Perseus, 2003).

28. Ibid., 126.

29. Malcolm Knowles, The Modern Practice of Adult Education: Andragogy versus Pedagogy (New York: Association Press, 
1970); and Malcolm Knowles, The Adult Learner: A Neglected Species (Houston: Gulf, 1973).

30. Laird, Naquin, and Holton, Approaches to Training and Development, 139.

31. Special issue devoted to training, The Journal of European Industrial Training 13, no. 2 (1989).

32. "Job Analysis Principles," The Journal of European Industrial Training 13, no. 2 (1989): 5.

33. Donna Kotsopoulos, "Mathematics Discourse: 'It's Sounds Like Hearing a Foreign Language," Mathematics Teacher 101, no. 4 (Nov. 2007): 301-5.
34. Ibid., 302.

35. Nancy Maresh, "Breathing Life into Adult Learning" in The ASTD Handbook of Training Design and Delivery: A Comprehensive Guide to Creating and Delivering Training Programs, Instructor-Led, Computer-Based, or Self-Directed, ed. George M. Piskurich, Peter Beckschi, and Brandon Hill (New York: McGraw-Hill Professional, 2000): 3-27.

36. Ibid., 24.

\section{Appendix A. Bibliographic Terminology}

Please fill in this worksheet by identifying the information you find on the title page and/or verso of the books provided for this exercise. Not every book will have all of these bibliographic elements.

1. What is the title proper?

2. Is there other title information? If so, what it it?

3. Is there is a statement of responsibility? If so, what is it?

4. Is there an edition statement? If so, what is it? Is there more than one on the book? (Check covers, title page, and the verso)

5. Where was the book published? Is there more than one place of publication? (List it/them)

6. Who is the publisher? Is there more than one? (List it/them)

7. Is there a date of publication? Is it a true date of publication, a copyright date, or a printing date? (If there is one or more, list them and indicate what kind of date it is/they are)

8. Is there a series statement? (Check the book covers, half-title page, verso, etc.) If so, what is it?

\section{Appendix B. MARC Guide}

Here is an overview of the MARC record. It contains the fields and subfields you will likely see every day.

\section{MARC Field}

010

040

020

041

043

$05000^{*}$

$05014^{* * *}$

1001

$24510^{*}$

$2461^{*}$

250

260

300

4400

4900

\section{MARC Subfield}

\$a Library of Congress control number

$\$ \mathrm{a}$ Who cataloged the record $\$ \mathrm{c}$ Who put the record in the database $\$ \mathrm{~d}$ Any library that has made changes to the record $\$$ a ISBN \$z Incorrect ISBN

$\$$ a Coded information about foreign languages involved in the text

$\$$ a Coded information about the geographic area described in the text

$\$ \mathrm{a}$ LC call number supplied by the Library of Congress $\$ \mathrm{~b}$ Cutter and year

$\$$ a LC call number supplied by another library $\$$ b Cutter and year

\$a Author last name, First name, \$q (first and middle name spelled out), \$d date of birth and/or death.

\$a Title proper : $\$$ b other title information/\$c Author's name (all 3 transcribed exactly from the title page)

$\$ \mathrm{i}$ (explanatory phrase, if needed) : \$a Titles found on the cover, spine, etc. (no period at the end)

Edition statement

$\$$ a Place of publication : \$b Publisher, \$c date of publication

\$a number of pages : \$b illustrations; $\$ \mathrm{c}$ size $+\$$ e accompanying material (e.g., teacher’s guide)

\$a Series title; \$vv. 75 OR

\$a Series title; \$v no. 15 OR 


\title{
Appendix B. MARC Guide (cont.)
}

\author{
MARC Field \\ 4901 \\ 500 \\ 504 \\ 505 \\ $60010^{* * *}$ \\ 6500 \\ 6510 \\ $7 \mathrm{xx}^{* * * *}$ \\ $830 \# 0$ \\ * The second indicator varies \\ * The first indicator varies \\ *** Both indicators vary

\section{MARC Subfield} \\ \$a Series title ; \$v Bd. 4 (This requires a field 830 in the record) \\ General notes \\ Bibliography (and index) note \\ Contents note \\ Name of person (subject of the book) \\ Topical subject heading \$x general subdivision \$z Geographic subdivision \$y Time period \$v Genre \\ (e.g. Bibliography, Periodical and so on) \\ Geographic Subject \\ Additional access points_-authors (may be persons, corporate bodies, conferences) and uniform titles \\ Series name as LC has decided it should be formulated ; \$v no. 16
}

\section{Appendix C. Selected Online Resources for Trainers}

\section{OCLC Tutorials}

OCLC is an excellent source of online tutorials. Connexion Client tutorials are found at www.oclc.org/support/training/ connexion/client/tutorial/default.htm. They include "Introduction to MARC Tagging" (www.oclc.org/support/training/ connexion/marc/default.htm) and "OCLC Connexion Client: Searching WorldCat" (www5.oclc.org/downloads/tutorials/ connexion/client/clsearch.html). Similar tutorials for OCLC Connexion Browser are found at www.oclc.org/support/training/ connexion/browser/tutorial.

\section{The Library of Congress}

LC has an introduction to MARC available called "Understanding MARC: Bibliographic Machine Readable Cataloging" (www.loc.gov/marc/umb). This is an excellent introduction that ends with a brief self-test that the trainee can do. The answers are provided. If the new cataloger will eventually be doing any authority work, LC's "Understanding MARC: Authority Records: Machine Readable Cataloging" (www.loc.gov/marc/uma) will be equally useful.

\section{Miscellaneous Resources on the Web}

Ann Branton and Aiping Chen-Gaffey at the University of Southern Mississippi have created an interactive MARC 21 tutorial based on LC's "Understanding MARC" guide (www.lib.usm.edu/legacy/techserv/marc21_tutorial_ie).

Kathleen Wells and Nashaat Sayed, also at the University of Southern Mississippi, have created an interactive tutorial based on LC's "Understanding MARC Authority Records" (www.lib.usm.edu/legacy/techserv/auth_tutorial). Infohio (Information Network for Ohio Schools) has made a series of very short, filmed Tag Tutors (www.infohio.org/UC/TagTutors). While the tutorials assume some very basic knowledge of cataloging on the part of the viewer, they are a nice supplement to the new cataloger's training. Unfortunately, only a few tags are covered and the division of the material is sometimes quirky. The script is available for each tag in either Word or PDF format.

The Idaho Commission for Libraries has also developed online training for nonprofessional library staff. While the "courses" cover much more than cataloging, Alternative Basic Library Education (ABLE) (http://libraries.idaho.gov/page/ alternative-basic-library-education-able) offers a unit on technical services that is aimed primarily at public and school libraries. While too basic to stand alone, it is a useful supplement that the trainee can consult any time. Each section within the unit is followed by a self-test that provides immediate feedback. Supplemental Basic Library Education (SABLE) (http:// libraries.idaho.gov/page/supplemental-alternative-basic-library-education-sable-program) offers a unit on cataloging music sound recordings. 